\title{
Peri-Partum Cardiomyopathy: Epidemiological, Clinical Aspects and Risk Factors in Semi-Urban Areas in Senegal
}

\author{
Simon Joel Manga', Diop Mohamed'1, S. L. Sy², Q. Te Indafa1 \\ ${ }^{1}$ Cardiology Department, Hospital de la Paix, Assane SECK University of Ziguinchor, Ziguinchor, Senegal \\ ${ }^{2}$ Cardiologie Department, Fann National University Center, Cheikh Anta Diop University, Dakar, Senegal \\ Email: mangasimon@yahoo.fr
}

How to cite this paper: Manga, S.J., Mohamed, D., Sy, S.L. and Te Indafa, Q. (2021) Peri-Partum Cardiomyopathy: Epidemiological, Clinical Aspects and Risk Factors in Semi-Urban Areas in Senegal. Open Access Library Journal, 8: e8050.

https://doi.org/10.4236/oalib.1108050

Received: October 4, 2021

Accepted: October 31, 2021

Published: November 3, 2021

Copyright $\odot 2021$ by author(s) and Open Access Library Inc.

This work is licensed under the Creative Commons Attribution International License (CC BY 4.0).

http://creativecommons.org/licenses/by/4.0/

\begin{abstract}
Introduction: Peri-partum cardiomyopathy is a rare cause of heart failure. The objective of this work was to describe the epidemiological, clinical aspects and risk factors associated with peri-partum cardiomyopathy in $\mathrm{Zi}$ guinchor. Methodology: This was a retrospective study from January 01, 2015 to April 30, 2020 at the Ziguinchor Peace Hospital. We included all patients hospitalized for heart failure between the 8th month of pregnancy and the first 5 months postpartum. Results: We had recorded 32 cases of PPCM, i.e. an inpatient prevalence of $2.3 \%$. The average age of our patients was 27.19 \pm 8.082 years. The multiparous $(43.7 \%)$ were the most represented. Twin pregnancy was present in $28.1 \%$ of cases. Clinically, the condition occurred within the first three months postpartum in $28.1 \%$ of cases. The clinical picture was that of global heart failure in $87.5 \%$ of cases. On cardiac ultrasound, the average end diastolic diameter of the left ventricle was $58.9 \pm 4.98 \mathrm{~mm}$ and the average systolic ejection fraction of the left ventricle was $33.19 \% \pm$ $8.24 \%$. The treatment was mainly based on diuretics (100\%) and ACE inhibitors (93.8\%). After 6 months, $82.1 \%$ of patients had recovered normal left ventricular systolic function. Multiple pregnancies, age over 30, and twinning were the risk factors for PPCM in our patients. Conclusion: PPCM is a rare cause of heart failure and its overall prognosis is favorable in Ziguinchor.
\end{abstract}

\section{Subject Areas}

Cardiology

\section{Keywords}

Cardiomyopathies, Heart Failure, Peri-Partum, Senegal 


\section{Introduction}

Peripartum cardiomyopathy (PPCM) is a hypokinetic dilated heart disease occurring during pregnancy and defined as heart failure associated with ultrasound signs of left ventricular dysfunction (ejection fraction $<45 \%$ ) without other identified causes [1]. The incidence of PPCM varies greatly between ethnic groups. It varies from 1 case per 400 births in the populations most at risk (South Africa and Haiti) to 1 case per 4000 births in the United States [2]. The frequency of PPCM is higher in sub-Saharan Africa than in other regions of the world [3].

Complete recovery is observed in half of the patients, while the other half will retain dilated cardiomyopathy responsible for more or less severe chronic heart failure [1]. In the literature, mortality at 2 years varies from 0 to $4 \%$ in the USA, to $15 \%$ in Haiti and $28 \%$ in black Africa [4].

In Senegal, in a study carried out in Dakar, Mbaye found a prevalence of $0.8 \%$ [5].

The etiology of the condition is still unknown, but there are several risk factors associated with PPCM.

The objective of this study is to describe the clinical characteristics of PPCM, to determine the risk factors and to assess the development at 6 months of patients followed for PPCM at the Peace Hospital of Ziguinchor.

\section{Methodology}

We carried out a retrospective study in the cardiology department of the Peace Hospital from January 1, 2015 to April 30, 2020.

We included in the study all patients hospitalized in the department for a heart failure syndrome confirmed by ultrasonography installed one month before or within five months after childbirth without any other etiology found. The data collection base consisted of hospitalized patient records and the parameters studied concerned socio-demographic data (age, gender, socio-economic level, consultation time), constants hemodynamics, functional signs as well as clinical examination data. The results of additional examinations, the factors favoring the risk of the occurrence of PPCM, treatment and hospital development were also studied.

The PPCM was defined by:

- the occurrence of congestive heart failure in the previous month or 5 months after childbirth;

- the lack of etiology found;

- the presence of echocardiographic signs attesting to left ventricular dysfunction, with LVEF $\leq 45 \%$ and/or cavity dilation with DTDVG $\geq 57 \mathrm{~mm}$.

Data analysis was performed with Statistical Package for Social Sciences (SPSS) software version 18. The descriptive study was carried out by calculating frequencies and proportions for qualitative variables and calculating means and standard deviations for quantitative variables. 
The analytical study was done with cross tables. To compare the frequencies, we used Pearson's Chi-square test or Fisher's two-tailed exact test according to their conditions of applicability with a significance level of $\mathrm{p}<0.05$.

We made sure that the confidentiality of study participants was ensured by using personal identification numbers on data collection forms instead of names. Personal identifiers will not be included in study reports. All study files will be kept confidential.

\section{Results}

In total, we collected 32 cases of peripartum cardiomyopathy during the study period, for a hospital prevalence of $2.3 \%$. PPCM accounted for $7 \%$ of causes of heart failure and $11.55 \%$ of cardiomyopathies.

The frequency of peripartum cardiomyopathy relative to the number of deliveries was 1 case per 250 deliveries.

The average age of our patients was $27.19 \pm 8.082$ years and the most represented age group was 30 to 39 years with $40.6 \%$ of cases.

Twin pregnancy was present in 9 patients, i.e. $28.1 \%$ of cases.

The average gestation was $3.38 \pm 2.56$ gestures with extremes of 1 and 10 and multigestes were predominantly represented with $46.9 \%$ of cases.

The majority of our patients had given birth by a low eutocic route with $81.3 \%$ of cases.

The average parity was $3.5 \pm 2.46$ children and the majority of our patients were multiparous with $43.7 \%$ of cases.

In all of our patients, symptoms appeared in the postpartum and 3 months postpartum in most cases (28.1\%).

Table 1 shows the main functional signs in our patients: dyspnea (100\%), cough $(68 \%)$ and chest pain $(40.6 \%)$ were the main symptoms.

The majority of patients presented with a picture of global heart failure with $87.5 \%$ of cases.

Cardiomegaly was observed in all patients with an average cardio-thoracic ratio of $0.62 \pm 0.73$.

Table 2 presents the main signs found on the electrocardiogram (ECG): sinus tachycardia (65.6\%), left atrial hypertrophy (28.1\%) and left ventricular hypertrophy (18.8\%) were the main signs found at the ECG.

Table 1. Distribution of patients according to the circumstances of discovery.

\begin{tabular}{ccc}
\hline Circumstances of discovery & Workforce & Percentage (\%) \\
\hline Dyspnea on exertion & 32 & 100 \\
Cough & 22 & 68.8 \\
Chest pain & 12 & 40.6 \\
Palpitations & 8 & 25 \\
Others & 9 & 28.1 \\
\hline
\end{tabular}


Table 2. Distribution of patients according to electrocardiographic signs.

\begin{tabular}{ccc}
\hline Electrocardiographic signs & Workforce & Percentage \\
\hline Sinus tachycardia & 21 & 65.6 \\
Left atrial hypertrophy & 9 & 28.1 \\
Left ventricular hypertrophy & 6 & 18.8 \\
Atrial flutter & 1 & 3.1 \\
Atrial fibrillation & 1 & 3.1 \\
Left bundle branch bloc & 1 & 3.1 \\
Others & 8 & 25
\end{tabular}

On cardiac ultrasound, the average telediastolic diameter of the left ventricle was $58.9 \pm 4.98 \mathrm{~mm}$.

The average left ventricular systolic ejection fraction (LVEF) was $33.19 \% \pm$ $8.24 \%$ and this was most often an average alteration in $46.9 \%$ of cases; LVEF was severely distorted in $43.8 \%$ of cases.

Therapeutically, the most prescribed drugs were diuretics (100\%), ACE inhibitors (93.8\%) and anticoagulants (81.3\%).

The average length of hospital stay for the patients was $9.56 \pm 6.09$ days.

The intra-hospital development was favorable in the majority of cases $(87.5 \%)$ and four patients (12.5\%) had died.

The clinical development at six months was favorable in 26 patients, or $92.9 \%$ of cases, and there were no patients lost to follow-up or rehospitalized.

LVEF at six months returned to normal in 23 patients, i.e. $82.1 \%$ of cases (Table 3).

The risk factors for CMPP in our patients were:

- age between 30 and 39 years old $(\mathrm{p}=0.023)$,

- a number of gestures between 4 and 6 gestures $(p=0.041)$,

- twinning $(\mathrm{p}=0.02)$,

- we did not find any poor prognostic factors in our study.

\section{Discussion}

CMPP is a rare etiology of heart failure. In our study, we reported 32 cases of CMPP in five years, an average of 7 cases per year, and CMPP represented 7\% of the heart failure causes. NIAKARA in Ouagadougou [6], reported 32 cases of CMPP in four years i.e. on average 8 cases per year and in Benin, ADJAGBA [7] reported 38 cases over four years and 7 months, i.e. on average 8.08 cases per year. The affection appears to be rarer in Europe, where CMPP represents $8 \%$ of patients referred for systolic heart failure result and $1 \%$ of patients with non-ischemic cardiomyopathy [8]. This confirms the claim that the frequency of CMPP is higher in sub-Saharan Africa than in other regions of the world. Good collaboration between gynecologists-obstetricians and cardiologists should give us a real idea of the CMPP prevalence in our regions. 
Table 3. Evolution of the left ventricular ejection fraction at 6 months.

\begin{tabular}{ccc}
\hline Evolution of LVEF at 6 months & Workforce & Percentage \\
\hline Moderate LV dysfunction & 4 & 14.3 \\
Severe LV dysfunction & 1 & 3.6 \\
Normal & 23 & 82.1 \\
Total & 28 & 100 \\
\hline
\end{tabular}

LV: Left ventricle; LVEF: Left ventricular ejection fraction.

CMPP is presented in a picture of heart failure most often immediately after childbirth and more rarely during the last month of pregnancy. In our study, the first signs of HF were postpartum in all of our patients and 3 months postpartum in most cases (28.1\%). In the ADJAGBA' study [7], 87.9\% of symptoms occurred in the postpartum and in those of IOP [9], 90.24\% of patients reported the symptoms in the postpartum' occurrence.

In our study, the clinical presentation was essentially that of global heart failure with $87.5 \%$ of cases. ADJAGBA [7] found $84.2 \%$ of global heart failure and in the study of PIO [7], global heart failure was found at $65.85 \%$. The classic picture of CMPP is that of global heart failure, sometimes purely left-handed, occurring in the last month of pregnancy or the 5 months of postpartum, generally severe and extremely rapid onset, sometimes on a few hours [8]. Hence the importance of a good sensitization of health professionals on the monitoring of women after childbirth in order to detect early the signs that could point to heart failure and thus allow a precocious management.

Since the electrocardiogram does not show specific signs, the cardiac ultrasound is the key examination for diagnostic confirmation. This important diagnostic tool is not often available in our regions and thus constitutes a handicap in the early diagnosis of CMPP.

The therapy implemented in our study does not offer any specificity compared to other causes of heart failure and to other studies.

The hospital lethality was $12.5 \%$ in our study versus $15.3 \%$ in the study of FETT in Haiti [10] and 4.88\% in the study of PIO [9] in Togo. In the literature, mortality at 2 years varies from 0 to $4 \%$ in the USA, to $15 \%$ in Haiti, and $28 \%$ in black Africa [4].

After six months, $82.1 \%$ of our patients had recovered normal left ventricular function. In the ADJAGBA study [7], this remission was observed in $31.6 \%$ of cases within an average of twenty-one months. According to several studies, the predictive factors of poor myocardial recovery are a very impaired LVEF, a very dilated left ventricle and the existence of high blood pressure (hypertension) during pregnancy [11]. In our study, gestational hypertension was found in $37.5 \%$ of cases, the mean end diastolic diameter of the left ventricle was 58.94 $\mathrm{mm}$ and $43.8 \%$ of our patients had severely impaired LVEF.

The long-term development is unpredictable: an ad integrum restoration of 
cardiac function is observed in half of the cases. The lack of recovery of full cardiac function within six months postpartum indicates a progression to chronic cardiomyopathy [1] [8]. The risk factors associated with CMPP classically described in the literature are advanced maternal age (over thirty years), multiparity, twin pregnancies, African origin, obesity, preeclampsia, gravidic high blood pressure and prolonged tocolysis [8]. The risk factors associated with CMPP in our study were maternal age over thirty years, multiparity and twin pregnancies. Knowledge or understanding of these risk factors should allow increased monitoring of these patients during pregnancy in our region.

Study limits: The retrospective nature of the study and the small size of our sample were the limits of this study.

\section{Conclusions}

The objective of this work was to describe the epidemiological, clinical and risk factors associated with peri-partum cardiomyopathy in Ziguinchor. Our patients were young, multiparous and a third of them had twin pregnancies. They're most often represented in a picture of global heart failure in the postpartum period. The cardiac ultrasound allowed us to make the diagnosis and follow the progress of our patients under treatment. Her overall long-term prognosis was good with recovery of myocardial function in most cases. However, PPCM can cause severe heart failure with significant mortality.

The statement of current knowledge on the subject

- CMPP is a rare cause of heart failure that affects young women.

- More common in people of African descent.

- Cardiac ultrasound is the key examination.

- Favorable evolution in general.

\section{Contribution of our study to knowledge}

- Our study confirmed that advanced age (over 30 years), multiparity and twin pregnancies were risk factors associated with PPCM.

- More favorable development at six months than in the general literature with treatment similar to that of primary dilated cardiomyopathy.

\section{Conflict of Interest}

The authors declare no conflict of interest.

\section{Authors' Contribution}

All the authors contributed to the conduct of this work. All authors have read and approved the latest version of this manuscript.

\section{References}

[1] Vanzetto, G., Martin, A., Bouvaist, H., Marlière, S., Durand, M. and Chavanon, O. (2012) Cardiomyopathie du péri-partum: Une entité multiple. La Presse Médicale, 41, 613-620. https://doi.org/10.1016/j.lpm.2012.03.014 
[2] Brar, S.S., Khan, S.S. and Sandhu, G.K. (2007) Incidence, Mortality, and Racial Differences in Peripartum Cardiomyopathy. American Journal of Cardiology, 100, 302-304. https://doi.org/10.1016/j.amjcard.2007.02.092

[3] Bahloul, M., Ahmed, M.N. and Laaroussi, L. (2009) Myocardiopathie du péri-partum: Incidence, physiopathologie, manifestations cliniques, prise en charge et pronostic. Annales Françaises d' Anesthésie et de Réanimation, 28, 44-60. https://doi.org/10.1016/j.annfar.2008.11.001

[4] Davis, M.B., Arany, Z. and McNamara, D.M. (2020) Peripartum Cardiomyopathy JACC State of Art Review. Journal of the American College of Cardiology, 75, 207-221. https://doi.org/10.1016/j.jacc.2019.11.014

[5] Mbaye, A., Ndiaye, Y., Monkam, M.A., Ndiaye, M., Cissé, A.F. and Kouamé, I. (2013) Cardiomyopathie du peripartum: À propos de 47 cas au service de cardiologie de l'hôpital général de grand Yoff de Dakar au Sénégal. Cardiologie Tropicale, $143,43$.

[6] Niakara, A., Belemwire, S., Nebie, L.V.A. and Drabo, Y.J. (2000) Cardiomyopathie du post-partum de la femme noire africaine: Aspects épidémiologiques, cliniques et évolutifs de 32 cas. Cardiologie Tropicale, 104, 69-73.

[7] Adjagba, P.M., Vlavonou, M.I.D., Codjo, L., Sonou, A., Hounkponou, M. and Bognon, R. (2017) Cardiomyopathie du péripartum au service de cardiologie du CNHU-HKM, Cotonou, Bénin. Cardiologie Tropicale, 149, 1-7.

[8] Mouquet, F. and Bouabdallaoui, N. (2015) Cardiomyopathie du péripartum. La Presse Médicale, 44, 798-804. https://doi.org/10.1016/j.lpm.2015.05.010

[9] Pio, M., Afassinou, Y., Baragou, S., Akue, E.G., Péssinaba, S. and Atta, B. (2014) Particularités de la cardiomyopathie du péripartum en Afrique: le cas du Togo sur une étude prospective de 41 cas au Centre Hospitalier et Universitaire Sylvanus Olympio de Lomé. Pan African Medical Journal, 17, 245. https://doi.org/10.11604/pamj.2014.17.245.3058

[10] Fett, J.D., Christie, L.G., Carraway, R.D. and Murphy, J.G. (2005) Five Year Prospective Study of the Incidence and Prognosis of Peripartum Cardiomyopathy at a Single Institution. Mayo Clinic Proceedings, 80, 1602-1606. https://doi.org/10.4065/80.12.1602

[11] Barton, A., Docherty, K., Campbell, R., Simpson, J., Jackson, A. and Dalzell, J. (2019) Prevalence and Predictors of Myocardial Recovery in Peripartum Cardiomyopathy: A Systematic Review. JACC, 73, 842. https://doi.org/10.1016/S0735-1097(19)31449-4 